\title{
Three-year pot culture of Epipactis helleborine reveals autotrophic survival, without mycorrhizal networks, in a mixotrophic species
}

\author{
Michał May ${ }^{1} \cdot$ Marcin Jąkalski $^{1} \cdot$ Alžběta Novotná $^{1,2} \cdot$ Jennifer Dietel ${ }^{3} \cdot$ Manfred Ayasse $^{3} \cdot$ Félix Lallemand $^{4}$. \\ Tomáš Figura $^{4,5}$ • Julita Minasiewicz ${ }^{1}$ - Marc-André Selosse ${ }^{1,4}{ }_{(\mathbb{D}}$
}

Received: 5 October 2019 / Accepted: 10 January 2020 / Published online: 21 January 2020

(C) The Author(s) 2020

\begin{abstract}
Some mixotrophic plants from temperate forests use the mycorrhizal fungi colonizing their roots as a carbon source to supplement their photosynthesis. These fungi are also mycorrhizal on surrounding trees, from which they transfer carbon to mixotrophic plants. These plants are thus reputed difficult to transplant, even when their protection requires it. Here, we take profit of a successful ex situ pot cultivation over 1 to 3 years of the mixotrophic orchid Epipacis helleborine to investigate its mycorrhizal and nutrition status. Firstly, compared with surrounding autotrophic plants, it did not display the higher $\mathrm{N}$ content and higher isotopic $\left({ }^{13} \mathrm{C}\right.$ and $\left.{ }^{15} \mathrm{~N}\right)$ abundance that normally feature mixotrophic orchids because they incorporate $\mathrm{N}$-, ${ }^{13} \mathrm{C}$-, and ${ }^{15} \mathrm{~N}$-rich fungal biomass. Second, fungal barcoding by next-generation sequencing revealed that the proportion of ectomycorrhizal fungi (expressed as percentage of the total number of either reads or operational taxonomic units) was unusually low compared with E. helleborine growing in situ: instead, we found a high percentage of rhizoctonias, the usual mycorrhizal partners of autotrophic orchids. Altogether, this supports autotrophic survival. Added to the recently published evidence that plastid genomes of mixotrophic orchids have intact photosynthetic genes, this suggests that at least some of them have abilities for autotrophy. This adds to the ecological plasticity of mixotrophic plants, and may allow some reversion to autotrophy in their evolution.
\end{abstract}

Keywords Mycoheterotrophy $\cdot$ Mycorrhizae $\cdot$ Orchid transplantation $\cdot$ Rhizoctonia $\cdot$ Stable isotopes $\cdot{ }^{13} \mathrm{C} \cdot{ }^{15} \mathrm{~N}$

\section{Introduction}

Some plants from temperate forests display a mixotrophic nutrition that relies on both their photosynthates and resources extracted from the mycorrhizal fungi colonizing their roots

Marc-André Selosse

ma.selosse@wanadoo.fr

1 Faculty of Biology, University of Gdańsk, ul. Wita Stwosza 59, 80-308 Gdańsk, Poland

2 Present address: Faculty of Science, University of South Bohemia, Branišovská 31, 37005 České Budějovice, Czech Republic

3 Institute of Evolutionary Ecology and Conservation Genomics, University of Ulm, Albert-Einstein Allee 11, D-89081 Ulm, Germany

4 Institut de Systématique, Evolution, Biodiversité (ISYEB), Muséum national d'Histoire naturelle, CNRS, Sorbonne Université, EPHE, CP 39, 57 rue Cuvier, F-75005 Paris, France

5 Department of Experimental Plant Biology, Faculty of Science, Charles University, Viničná 5, 12844 Prague, Czech Republic (for reviews, see (Selosse and Roy 2009; Selosse et al. 2016; Jacquemyn and Merckx 2019). These plants belong to the orchid (e.g., from the Neottieae tribe) and Ericaceae families and are also called partial mycoheterotrophs, because the heterotrophic nutrition using carbon from mycorrhizal fungi is called mycoheterotrophy (Hynson et al. 2013). Such mixotrophic plants rely on the ability of mycorrhizal fungi to establish networks between plants of different species, due to a low mycorrhizal specificity: the so-called mycorrhizal networks (Selosse et al. 2006; Simard et al. 2012) allow fungi to gain nutrients on some plants and to deliver part of it to others. Mixotrophic temperate plants rely on the network formed by ectomycorrhizal fungi, which also associate with surrounding trees (Selosse and Roy 2009).

Five lines of evidence demonstrated this mixotrophic status. Firstly, the mixotrophic plants shifted from the usual mycorrhizal fungi of their respective family (e.g., the rhizoctonias in orchids; (Dearnaley et al. 2012)) to ectomycorrhizal taxa, establishing mycorrhizal networks with nearby trees (Hynson et al. 2013). Secondly, the (hitherto elusive) compounds provided by ectomycorrhizal fungi to mixotrophs is naturally 
enriched in ${ }^{13} \mathrm{C}$ as compared with photosynthates, and the biomass of mixotrophic plants is thus enriched in ${ }^{13} \mathrm{C}$ compared with that of autotrophic plants (Gebauer and Meyer 2003; Bidartondo et al. 2004; Julou et al. 2005; Hynson et al. 2013); note that the biomass acquired by mycoheterotrophy is often also enriched in ${ }^{15} \mathrm{~N}$ ). Importantly, ${ }^{13} \mathrm{C}$ abundance in mixotrophs can be used to calculate the percentage of mycoheterotrophy in each organ and season (Gebauer and Meyer 2003; Gonneau et al. 2014) or in different light environments (Preiss et al. 2010; Gonneau et al. 2014). Thirdly, beyond isotopic evidence of a raw $\mathrm{C}$ flow from the fungus to the orchid, the survival of rare achlorophyllous variants, in mixotrophic Neottieae orchids at least, demonstrates a net flow in favor of the plant: these achlorophyllous variants survive well (Selosse et al. 2004; Julou et al. 2005; Lewis 2015; Shefferson et al. 2016), but produce a limited fruit set (Salmia 1989; Roy et al. 2013; Gonneau et al. 2014). Fourthly, green mixotrophic individuals display a limited photosynthesis rate, even under the compensation point (where photosynthesis equals respiration), due to the shade of the tree canopy (Julou et al. 2005) or to limited intrinsic photosynthetic abilities (Girlanda et al. 2006). Fifthly, mixotrophs often contain more nitrogen $(\mathrm{N})$ as compared with autotrophic, non-N fixing plants, probably because (i) plant respiration eliminates $\mathrm{C}$ and thus concentrates $\mathrm{N}$ from the biomass received from fungi, as described in heterotrophs, and/or (ii) the fungal biomass is likely already N-rich (Abadie et al. 2006; Hynson et al. 2013).

Recently, a split use of the two (photosynthetic and mycoheterotrophic) resources by mixotrophic Neottieae orchids was revealed, based on the variations of ${ }^{13} \mathrm{C}$ abundance in various organs and labeling of photosynthates in situ. Photosynthates produced after leaf expansion are mostly used for aerial parts, leaves, and fruits which are green before ripening (Roy et al. 2013; Bellino et al. 2014). Mycoheterotrophic resources are mostly used for underground roots and rhizomes (Gonneau et al. 2014): see Fig. 5 therein), as well as for elaboration of starch reserves (Lallemand et al. 2019a). This explains why achlorophyllous variants produce fewer seeds (Roy et al. 2013), but have good rhizome survival (Shefferson et al. 2016).

Mixotrophic orchids thus strongly depend on mycorrhizal networks for survival, and these results in some difficulties in transplantation attempts, as reported by Sadovsky (1965) for mixotrophic Neottieae. This puts constraints on protection and transplantations to save populations menaced by changes in land use. Yet, there are seldom examples of successful transplantation: for example, Delforge $(2016,2017)$ reports that two Epipactis helleborine individuals (Neottieae tribe) survived transplantation to a forest edge environment the first year and even flowered. While one individual then disappeared, the other one persisted over 6 years at least (Delforge 2016, 2017). Furthermore, some commercial nurseries sell mixotrophic Epipactis spp. grown in pots, such as $E$. helleborine, although every time we accessed these products $(n=2)$ they turned out to belong to E. palustris, a related but autotrophic species (Lallemand et al. 2018). The Epipactis helleborine orchid species usually harbors a dominance of ectomycorrhizal fungi in its roots (Bidartondo et al. 2004; Ogura-Tsujita and Yukawa 2008; Těšitelová et al. 2012; Jacquemyn et al. 2016; Jacquemyn and Merckx 2019) and, from many isotopic data, largely relies on mycoheterotrophy for its rhizome survival and growth of young shoots (Gebauer and Meyer 2003; Gonneau et al. 2014; Schiebold et al. 2017; Lallemand et al. 2019a); Xing et al. 2019), so that successful transplantation and pot culture appear unexpected.

Here, we used a common garden growth experiment to investigate the stability of the phenotype of various morphologically distinct subspecies of $E$. helleborine after transplantation (see Delforge 2016, for a review of these subspecies; the taxonomic outcome of this experiment will be reported elsewhere). Transplanted E. helleborine were successfully grown in pots placed in a common garden, where the absence of a mycorrhizal network prompted the questions of (1) their mycorrhizal associates after transplantation, and (2) their level of autotrophy. Using, respectively, metabarcoding methods to identify the fungal community in roots and isotopic and $\mathrm{N}$ abundance to characterize the autotrophy level, we evidence here autotrophic survival of the mixotrophic E. helleborine.

\section{Material and methods}

\section{E. helleborine culture ex situ}

The investigated plants were harvested with 2 L of undisturbed soil surrounding each plant, in 2013 or 2015 (Table 1). Their forests of origin were mixed but dominated by Fagus sylvatica, with a dense canopy as is typical for the ecology of this species in Central Europe (Těšitelová et al. 2012). The plants belonged to three different subspecies of E. helleborine (see Table 1 and Delforge 2016, for a review of these subspecies and their debated taxonomic status). After cutting two long roots, the plants were individually placed in square pots $(18 \times 18 \mathrm{~cm}$, height $20 \mathrm{~cm}$; Fig. 1) filled with the soil collected at the same time as the orchids. After potting, orchids were deposited at a propagation bed of the Botanical Garden of the University of Ulm on a 5-cm layer of sand in order to prevent waterlogging. Pots were moved weekly to limit the ability of local soil fungi to establish permanent links with the plants (indeed, some ectomycorrhizal trees grow at a distance $>5 \mathrm{~m}$ in the garden). They were watered daily and put below a large grid covered with an aluminum top in order to provide shadier conditions (distance to the top of highest orchids was $75 \mathrm{~cm}$ ). Despite shading, plants grew in a luminous conditions based on Ellenberg's indicator value $(7.0 \pm$ 
Table 1 Origin and sampling of the $E$. helleborine individuals from the Botanical Garden of the University of Ulm investigated in this study (sampling in 2016)

\begin{tabular}{|c|c|c|c|c|}
\hline $\begin{array}{l}\text { Transplantation to } \\
\text { the Botanical Garden Ulm }\end{array}$ & Sub-species & $\begin{array}{l}\text { Sampled } \\
\text { individuals* }\end{array}$ & Forest of origin & Geocodes \\
\hline June 2015 & E. helleborine type & $0 / 1$ & Ulm & $\begin{array}{l}48^{\circ} 24^{\prime} 05^{\prime \prime} \mathrm{N} \\
09^{\circ} 55^{\prime} 05^{\prime \prime} \mathrm{E}\end{array}$ \\
\hline July 2013 & E. helleborine minor & $5 / 1$ & Königsbronn & $\begin{array}{l}48^{\circ} 44^{\prime} 10^{\prime \prime} \mathrm{N} \\
10^{\circ} 05^{\prime} 31^{\prime \prime} \mathrm{E}\end{array}$ \\
\hline July 2013 & E. helleborine type & $5 / 1$ & Königsbronn & $\begin{array}{l}48^{\circ} 44^{\prime} 10^{\prime \prime} \mathrm{N} \\
10^{\circ} 05^{\prime} 31^{\prime \prime} \mathrm{E}\end{array}$ \\
\hline July 2013 & E. helleborine moratoria & $5 / 1$ & Ulm & $\begin{array}{l}48^{\circ} 24^{\prime} 05^{\prime \prime} \mathrm{N} \\
09^{\circ} 55^{\prime} 05^{\prime \prime} \mathrm{E}\end{array}$ \\
\hline
\end{tabular}

*Number of individuals sampled for leaf isotopic abundances/number of individuals sacrificed for fungal barcoding of root fungi and mycorrhiza isotopic abundances
0.63 ; mean \pm confidence interval) calculated on the basis of the plants spontaneously growing at the same place and in the same conditions (Brassica napus, Sinapis arvensis, Echinacea purpurea, E. pallida, Heracleum sphondylium, Lythrum salicaria, Agrimonia eupatoria, Campanula trachelium, C. persicifolia, C. medium, Taraxacum officinale, Leontodon autumnalis, Malva sylvestris, M. moschata, Verbascum densiflorum, V. phlomoides, Geranium sanguineum, Plantago major). Ellenberg's indicator value represents the preference of individual species, based on empirical field observations in Central Europe, ranging from 1 (deep shade) to 9 (full sunlight; Ellenberg et al. 1991).

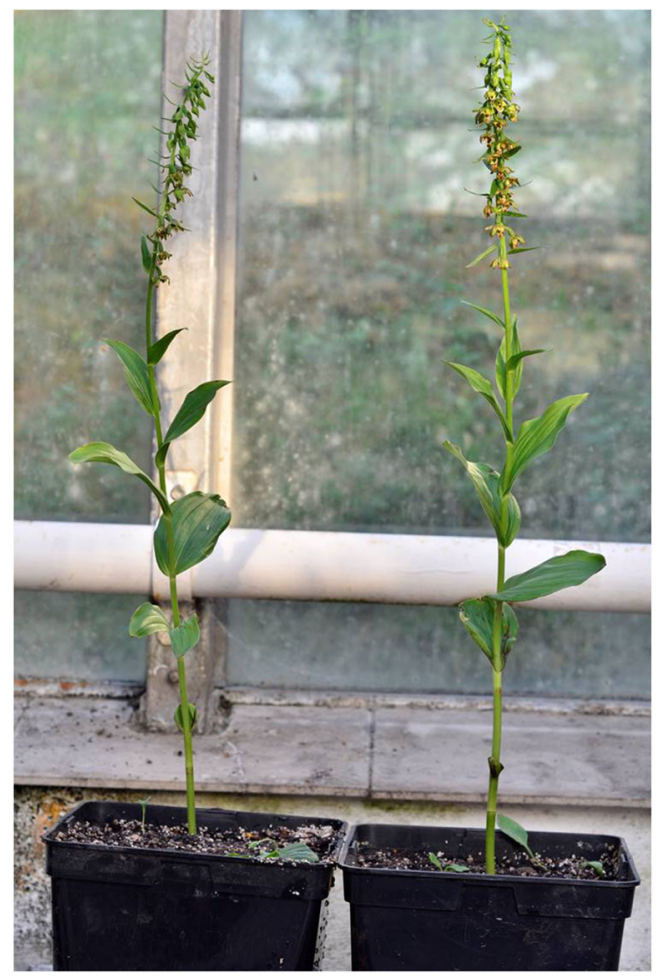

Fig. 1 Pot cultures of E. helleborine individuals investigated in this study (E. helleborine sampled in 2015 near Ulm, pictured July 2017)
Survival rate after transplantation in the garden was ca. $60 \%$, but surviving plants flowered in all years after sampling (vegetative and reproductive descriptions will be reported in a separate paper investigating the three different subspecies of E. helleborine).

\section{Stable isotope analyses}

We sampled about $1 \mathrm{~g}$ (fresh weight) of leaves from each E. helleborine individual in July 2016, 3 years after their transplantation to pot culture (Table 1). We also added for these analyses mycorrhizal roots of the four individuals sampled for fungal barcoding (see below and Table 1; two root pieces per individual). As a reference for autotrophic plants, we used weeds growing in the same pots, i.e., an unidentified Arabidopsis species, Plantago major, and Taraxacum sp. The two latter species form arbuscular mycorrhizas while the first one is not mycorrhizal but harbors various root endophytes as do other Brassicaceae (Almario et al. 2017). Six replicates from independent plants were sampled for each species. To minimize environmental variations influencing ${ }^{13} \mathrm{C}$ abundance, all leaf samples were collected at a similar light level and at a similar distance from the pot soil, i.e., under the grid covered with aluminum. Samples were ground in $2-\mathrm{mL}$ Eppendorf tubes in a ball mill MM200 (Retsch Gmbh, Haan, Germany) and analyzed for total $\mathrm{N}$ concentration, as well as ${ }^{13} \mathrm{C} /{ }^{12} \mathrm{C}$ and ${ }^{15} \mathrm{~N} /{ }^{14} \mathrm{~N}$ ratios using an elemental analyzer (EA) coupled to a ThermoFinnigan DeltaV Advantage Continuous-Flow Isotope-ratio mass spectrometer, and expressed as $\delta$-values (Hynson et al. 2013). Isotope values were calibrated using internal calibrated standards (EDTA and ammonium oxalate). The standard deviations of the replicated standard samples were $0.024 \%$ of ${ }^{13} \mathrm{C}$ and $0.199 \%$ 。 for ${ }^{15} \mathrm{~N}$. Statistical analyses were performed using R environment for statistical computing (R Core Team 2015). Analysis of variance (ANOVA) was used to evaluate differences in mean $\delta^{13} \mathrm{C}, \delta^{15} \mathrm{~N}$, and $\% \mathrm{~N}$ among species from a given site 
(function aov $\{$ stats $\}$ ). The alpha type I error threshold was set at 0.05 .

\section{Identification of $E$. helleborine root fungi}

For metabarcoding of root fungi by next-generation sequencing (NGS), roots of four plants (see Table 1; i.e., two plants from each site of origin) were harvested in 2016, i.e., 1 or 3 years after transplantation to pot culture (Table 1). This sampling was intended to limit damage in the common garden growth experiment. Roots were screened for mycorrhizal colonization, and 4 independent colonized root pieces were submitted to DNA extraction for the subsequent assessment of fungal communities as in Schneider-Maunoury et al. (2018, 2019). We amplified the ITS2 region by using the two general primer pairs ITS3/ITS4-OF and ITS86-F/ITS4, as such a choice of primers covers a large fungal set, including orchid mycorrhizal fungi (Waud et al. 2014; Jacquemyn et al. 2016), but not necessarily arbuscular mycorrhizal ones, known to be underrepresented in orchids. The four pooled amplicon libraries, generated in a PCR reaction (see Schneider-Maunoury et al. (2018) for detailed parameters), were sequenced with an Ion Torrent sequencer (Life Technologies, Carlsbad, USA). In brief, the downstream analyses included at first a R-OTU (Reference Operational Taxonomic Unit) database generation utilizing the full-length amplicons only, i.e., reads containing both the ITS86-F and ITS4 primers, in both types of amplicons (the primer pair ITS86-F/ITS4 resides within the stretch amplified by the ITS3/ITS4-OF pair), allowing a $25 \%$ error rate for primer recognition and a minimum required length of $200 \mathrm{bp}$. Trimmed sequences were clustered into ROTUs with SWARM (Mahé et al. 2014), followed by removal of singletons, as well as chimera removal with UCHIME (Edgar et al. 2011) against the UNITE database (Kõljalg et al. 2013). Next, reads from the original amplicon sets were extracted and trimmed if they contained the ITS86F and ITS4 primers, and assigned to R-OTUs using BLASTN (Altschul et al. 1990) with a $97 \%$ similarity threshold. Assigning a taxonomy to each R-OTU was finally accomplished by comparing the representative sequences of each R-OTU to the UNITE reference database using BLASTN with a $90 \%$ similarity threshold. The above-described steps were carried out using selected scripts from the QIIME package v1.9.1 (Caporaso et al. 2010), as well as home-made scripts. Representative sequences for each mycorrhizal OTU found in this study were submitted to GenBank under accession numbers MN459665-MN459894. OTUs were manually screened for possible orchid mycorrhizal families based on Dearnaley et al. (2012) and information of previously detected mycorrhizal fungi from the roots, germinating seeds and protocorms of various Epipactis species (Bidartondo et al. 2004; Selosse et al. 2004; Ogura-Tsujita and Yukawa 2008; Těšitelová et al. 2012; Jacquemyn et al. 2016; Jacquemyn and
Merckx 2019); we also included all potentially ectomycorrhizal fungi according to (Tedersoo et al. 2010; 2013). Analysis was restricted to these taxa. We tested the null hypothesis of no difference in the proportions of rhizoctonia and non-rhizoctonia fungi sequences and OTUs number among four groups represented by data from the present study, these from Těšitelová et al. (2012) and these from Jacquemyn et al. (2016 and 2019), i.e., whenever format of published data allowed respective comparisons: for this, we performed the chi-square test with Yate's correction followed by a pairwise proportional test with the Bonferroni correction. Proportions instead of raw sequences and OTU number data were applied in the calculation to normalize results between the studies.

\section{Results}

\section{Stable isotope analyses}

The leaf isotopic abundance in ${ }^{13} \mathrm{C}$ and ${ }^{15} \mathrm{~N}$ of the three subspecies of $E$. helleborine (Fig. 2a) did not differ significantly from those of the reference autotrophic Arabidopsis sp., Plantago major, and Taraxacum sp. growing in the same pots and conditions, whatever the sub-species (see statistics in caption of Fig. 2a). Mycorrhizal roots displayed the same ${ }^{13} \mathrm{C}$ abundance as leaves (Fig. 2b). The average total $\mathrm{N}$ content of $E$. helleborine was lower than that of the reference autotrophic species, significantly for Arabidopsis sp. and Plantago major (Fig. 3). Thus, neither $\mathrm{N}$ content nor isotopic abundances indicated any contribution of N-rich, ${ }^{13} \mathrm{C} /{ }^{15} \mathrm{~N}$-enriched biomass originating from ectomycorrhizal fungi in the aerial and root biomass of pot-cultivated $E$. helleborine individuals.

\section{Identification of $E$. helleborine root fungi}

The quality-filtered pyrosequencing data set comprised 584 OTUs represented by 613,118 sequences. After analysis, $88.9 \%$ of the total number of sequences $(544,929$ sequences, 454 OTUs) could be assigned to Ascomycota and Basidiomycota, and a relatively large representation of Glomeromycota (arbuscular mycorrhizal fungi; 11,646 sequences, 63 OTUs, $10.7 \%$ of all fungal OTUs) were recovered. Putatively orchid mycorrhizal according to Dearnaley et al. (2012) and/or ectomycorrhizal taxa covered 167 OTUs $(402,272$ sequences, $65.6 \%)$. Among these, we found the usual fungal associates of autotrophic orchids, the so-called rhizoctonias: from the three rhizoctonia families, Ceratobasidiaceae were ubiquitous and highly abundant (198,383 sequences, $49.3 \%$ of all sequences in this category; in all, 49 OTUs; Fig. 4); Serendipitaceae (1 OTU) occurred in 3 plants (but reached high abundance in only one of these); no Tulasnellaceae was found. Several ectomycorrhizal clades potentially mycorrhizal on 
a

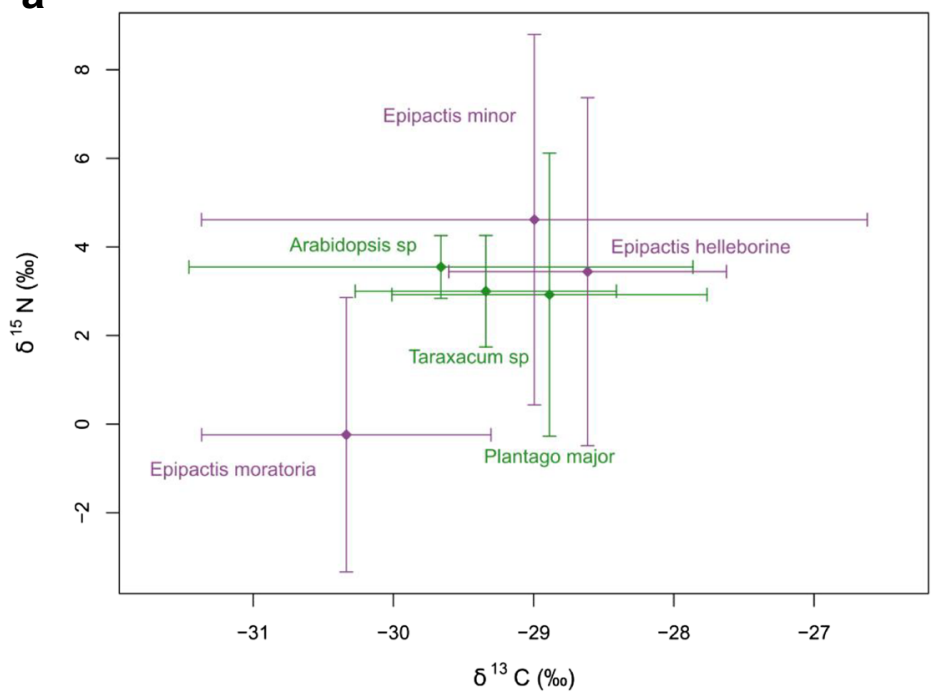

b

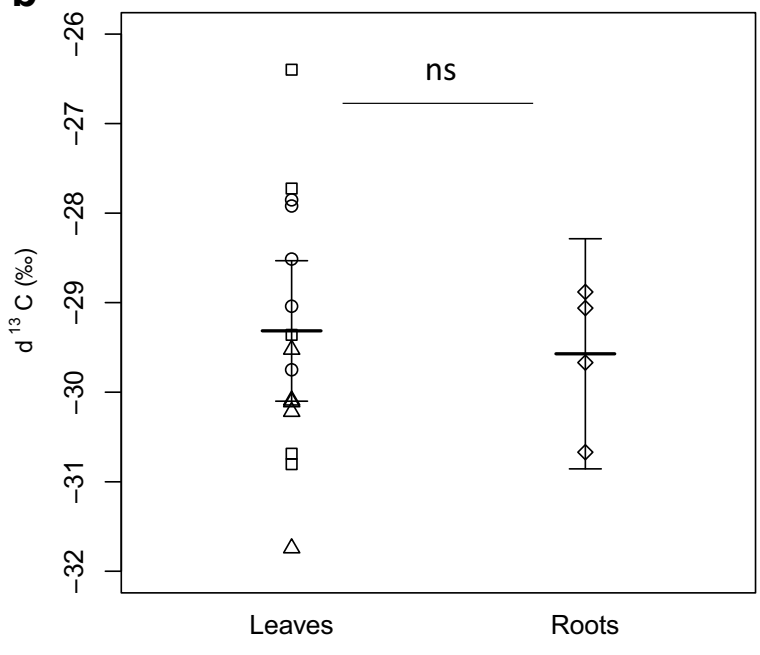

Fig. 2 Isotopic abundance of E. helleborine individuals (violet; $n=5$ replicates for leaves and $n=4$ for roots) and surrounding autotrophic weeds (green; $n=6$ replicates). a $\delta^{13} \mathrm{C}$ and $\delta^{15} \mathrm{~N}$ values of leaves (distinguishing the 3 sub-species). b $\delta^{13} \mathrm{C}$ of roots versus leaves of E. helleborine (all sub-species pooled). Bars represent the $95 \%$

E. helleborine were recorded. Helotiales $(76,164$ sequences, $18.9 \%)$ and Herpotrichellaceae $(33,708$ sequences, $8.4 \%$ ) were ubiquitous, although with different abundances from one plant to another, while other taxa occurred on some plants only (Fig. 4a), namely Tuberaceae (Tuber anniae, 14,380 sequences, 3.6\%, from 2 plants), Pyronemataceae (67,960 sequences, $16.9 \%$, from 4 plants), Sebacinaceae, Inocybe and Cortinarius (for these three taxa: 64 sequences, $0.01 \%$, from 3 plants; Fig. 4). The individuals transplanted to pot more recently (1 year of cultivation; column 1 in Fig. 4a) revealed more abundant ectomycorrhizal fungi than the ones cultivated for 3 years (columns $2-4$; respectively $70.65 \%$ of all sequences versus $48.18 \%$ on average): Pyronemataceae dominated in its fungal community (12 OTUs and 24,681 sequences). confidence intervals of the mean for each species. No significant difference was found between species for $\delta^{13} \mathrm{C}$ nor $\delta^{15} \mathrm{~N}$ (ANOVA; $F=1.50$ and $p=0.232$ for ${ }^{13} \mathrm{C} ; F=2.26$ and $p=0.086$ for ${ }^{15} \mathrm{~N}$ ), or between $E$. helleborine organs (to a Tukey honest significant difference test; $p=$ $0.65)$

On average, the proportion of rhizoctonias found in this study was significantly higher than that of other available studies (Table 2) calculated as sequence proportions $\left(\chi^{2}\right.$ $(0.05,3)=161.07 ; p<0.0001)$ or as OTU proportions $\left(\chi^{2}\right.$ $(0.05,2)=39.37 p<0.001)$.

\section{Discussion}

We observed 1- to 3-year survival in pots for E. helleborine, with normal development and flowering (Fig. 1; developmental traits will be reported later in a comparative study of E. helleborine subspecies) that correlates with (i) an unusually high abundance of rhizoctonias and (ii) isotopic and $\mathrm{N}$ signatures that do not differ from nearby autotrophic plants.
Fig. 3 Total $\mathrm{N}$ content of leaves of $E$. helleborine individuals ( $n=$ 5 replicates) and surrounding autotrophic weeds $(n=6)$. Different letters in brackets after the plant names indicate different content according to a Tukey honest significant difference test

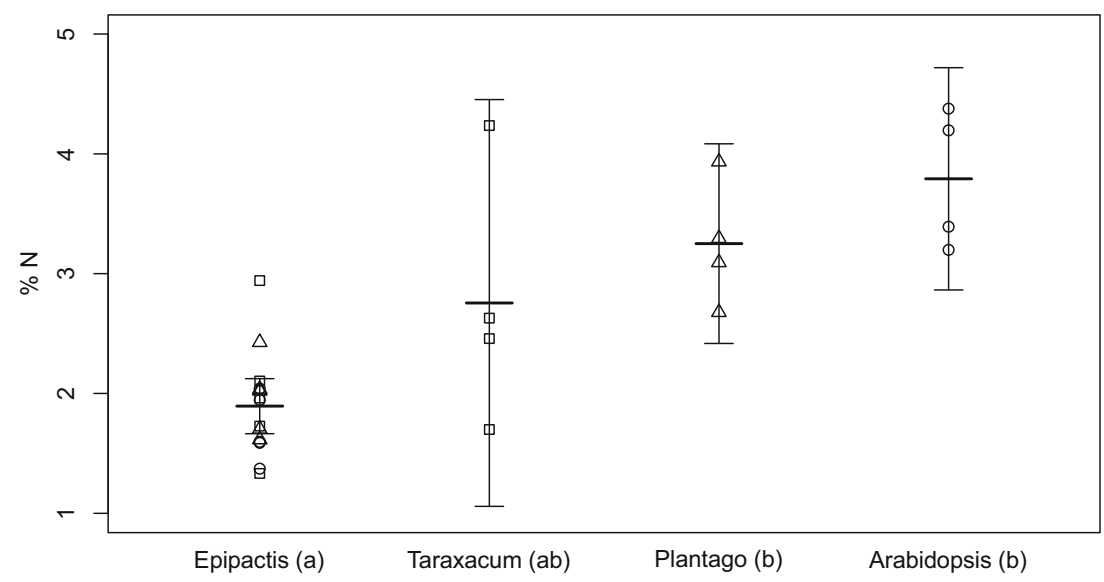


Fig. 4 Putative mycorrhizal fungal families (i.e., orchid mycorrhizal or ectomycorrhizal) detected in E. helleborine individuals from pot culture. Relative abundance of each mycorrhizal fungal family (i.e., orchid mycorrhizal or ectomycorrhizal) is calculated as the proportion of DNA sequences. a Communities for the four individuals (Table 1), namely: 1, E. helleborine (type) from Ulm after 1 year in pots; 2 , E. helleborine minor from Königsbronn; 3, E. helleborine (type) from Königsbronn; E. helleborine moratoria from $\mathrm{Ulm}$; the latter three were kept for 3 years in pot culture. b Total community found in the four barcoded E. helleborine individuals. The category "other" includes Sebacinaceae and unidentified Sebacinales, Inocybe and Cortinarius

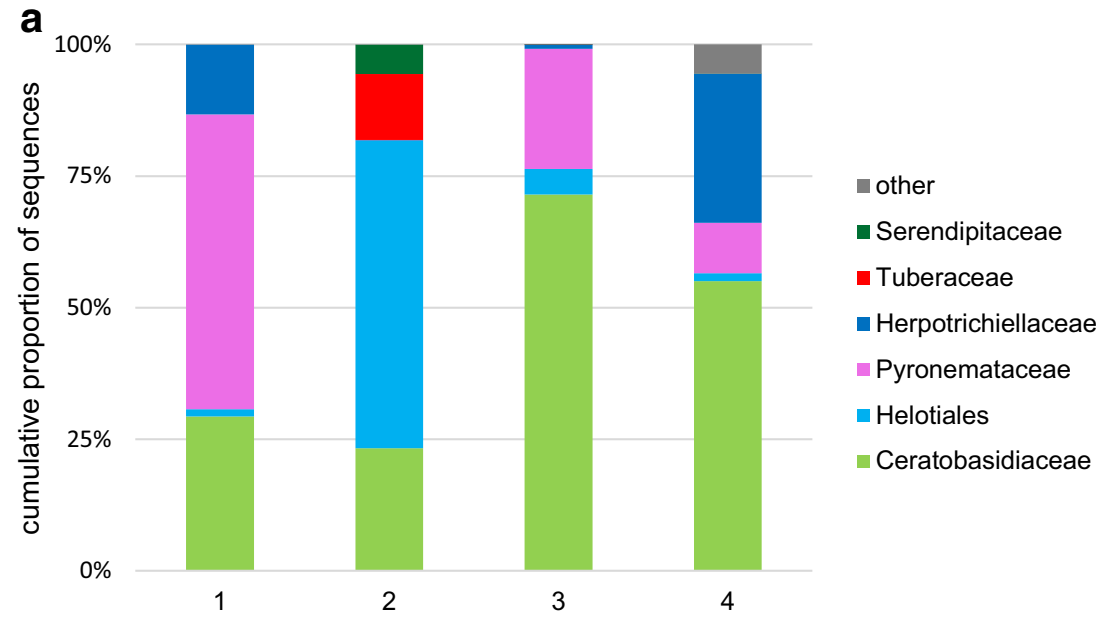

b

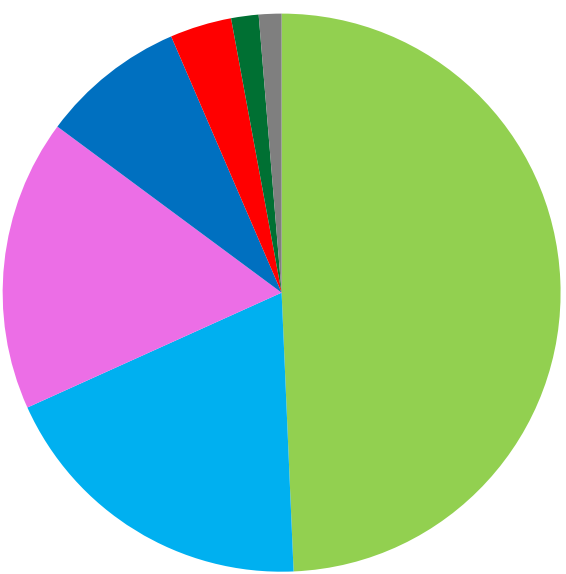

Ceratobasidiaceae Helotiales

- Pyronemataceae

- Herpotrichiellaceae

- Tuberaceae

- Serendipitaceae

other
Although this short-term experiment may reflect survival rather than a sustainable niche (i.e., we do not assess average life expectancy), we discuss these observations in terms of mycorrhizal interaction and physiology of E. helleborine, in the general framework of evolution and biological conservation of mixotrophic plants.

Table 2 Percentage of rhizoctonias versus non-rhizoctonia ectomycorrhizal taxa including species whose exact status, endophytic or ectomycorrhizal, is debated, such as Helotiales or

\section{Mycorrhizal fungi are dominated by rhizoctonias}

Pot-cultivated E. helleborine revealed a community of root mycorrhizal fungi (including some endophytes sensu Wilson 1995 , i.e., fungi colonizing the roots loosely without forming true mycorrhizas) qualitatively (= taxonomically) close to that

Herpotrichiellaceae. The value is calculated as percentage of reads (in italics) or as percentage of OTUs (bold, in brackets), which was not calculable for the work by Jacquemyn et al. (2016)

\begin{tabular}{|c|c|c|c|c|}
\hline Study: & Current study & Xing et al., 2019 & Jacquemyn et al. 2016 & Těšitelová et al. 2012 \\
\hline Growth conditions: & Pot culture & In natura & In natura & In natura \\
\hline Barcoding method: & NGS & NGS & NGS & Sanger (cloning) \\
\hline Rhizoctonia taxa & $\begin{array}{l}50.87 \% \\
{[29.9 \%]}\end{array}$ & $\begin{array}{l}3.30 \% \\
{[10.6 \%]}\end{array}$ & $0.03 \%$ & $\begin{array}{l}0 \% \\
{[0 \%]}\end{array}$ \\
\hline Non-rhizoctonia ecto-mycorrhizal taxa & $\begin{array}{l}49.13 \% \\
{[\mathbf{4 9 . 1 \%}]}\end{array}$ & $\begin{array}{l}96.70 \% \\
{[\mathbf{8 9 . 4 ]}}\end{array}$ & $99.97 \%$ & $\begin{array}{l}100 \% \\
{[\mathbf{1 0 0 \%}]}\end{array}$ \\
\hline Statistics* & $\begin{array}{l}a \\
{[\mathbf{a}]}\end{array}$ & $\begin{array}{l}b \\
{[\mathbf{b}]}\end{array}$ & $b$ & $\begin{array}{l}b \\
{[\mathbf{b}]}\end{array}$ \\
\hline
\end{tabular}

*Column with different letters differ significantly according to the chi-square test with Yate's correction $\left(\chi^{2}(0.05,3)=161.07, p<0.0001\right.$ for percentage of reads, $\chi^{\mathbf{2}}(\mathbf{0 . 0 5 , 3 )}=\mathbf{3 9 . 3 7}, \boldsymbol{p}<\mathbf{0 . 0 0 1}$ for percentage of OTUs), followed by pairwise proportional test with the Bonferroni correction 
reported from natural sites, but with striking quantitative differences. The finding of Glomeromycota, which normally form arbuscular mycorrhizae and are poorly targeted by the primers we used, was unexpected (but see e.g. Abadie et al. 2006): although their interaction with orchid roots is unexpected and unclear, we cannot exclude an asymptomatic colonization resulting from culture in the company of some arbuscular mycorrhizal weeds such as Taraxacum and Plantago spp. (a non-mycorrhizal colonization described in non-arbuscular mycorrhizal; Cosme et al. 2018).

On the one hand, the main taxa found here were also reported in situ for E. helleborine (see Bidartondo et al. 2004; Ogura-Tsujita and Yukawa 2008; Těšitelová et al. 2012; Jacquemyn et al. 2016; 2019). This includes rhizoctonias, which occur in many autotrophic orchids (Dearnaley et al. 2012): Ceratobasidiaceae that abound here are also reported in natura in E. helleborine. Ectomycorrhizal ascomycetes with possible endophytic abilities are also reported in natura in E. helleborine: taxa with this dual ecology include Tuber spp. (Schneider-Maunoury et al. 2018, 2019), Pyronemataceae (Hansen et al. 2013), Helotiales (Wang et al. 2006), and Herpotrichellaceae (such as Exophiala, which include the so-called dark septate endophytes; Jumpponen 2001). Ectomycorrhizal basidiomycota, finally, are usually much more diverse in natura than the few taxa found in this study (e.g., Těšitelová et al. 2012; Jacquemyn et al. 2016; 2019).

On the other hand, not only the diversity but also the abundance of ectomycorrhizal and/or endophytic taxa (asco- or basidiomycetes) is very low in pot-cultivated E. helleborine. A comparison with samplings in natura, barcoded by NGS or cloning, clearly supports this (Table 2). Of course, differences in methods and choice of primers for NGS may affect this comparison: however, our unpublished data set on E. helleborine from four forests sites in Europe (M.-A. Selosse, E. Delannoy \& J. Minasiewicz, unpubl; 15 individuals barcoded with exactly the same methods of analysis as in this study) revealed $99.1 \%$ of ectomycorrhizal/endophytic fungal sequences (difference with the current data significant, $\left.\chi^{2}(0.05,1)=64.9, p<0.05\right)$, representing $93.27 \%$ of the relative number of OTUs $\left(\chi^{2}(0.05,1)=16.4, p<0.001\right)$. Thus, the abundance of rhizoctonias, especially Ceratobasidiaceae, is unusually high in pot cultures (Table 2). Unfortunately, the composition of the root mycorrhizal community of the E. helleborine populations of origin (Table 1) at the time of sampling, which may predispose to this composition, remains unknown.

The finding of few potentially ectomycorrhizal taxa is unexpected in these pots where C-providing plant hosts are lacking. Indeed, mixotrophic orchids are unlikely to give them carbon, and instead even exploit them (see discussion below). We do not believe that contamination explains our data, but we consider three non-exclusive possibilities. Firstly, ectomycorrhizal taxa may be surviving here, perhaps declining over time: indeed, they are more numerous in the plants transplanted 1 year before (especially Pyronemataceae), but a firm conclusion cannot be drawn from this single plant. Secondly, ectomycorrhizal taxa may colonize the pot from the soil, since some ectomycorrhizal trees exist at some distance in the surroundings: however, we did not see any direct contact of pots with the soil, which was limited by (i) a layer of sand and (ii) weekly moving of the pots. Yet, we cannot exclude colonization by transient contacts reaching the orchid roots. Thirdly, there is increasing evidence that several ectomycorrhizal fungi, beyond the ascomycetous taxa mentioned above, also have endophytic abilities, i.e., colonize the roots of non-ectomycorrhizal plants in a loose way (for indirect evidence and a review on this, see Schneider-Maunoury et al. 2018, 2019; Selosse et al. 2018). This especially applies to the genus Tuber (Gryndler et al. 2014; SchneiderMaunoury et al. 2018, 2019), although this is not demonstrated for Tuber anniae, the North American species recently found to occur also in Europe (Wang et al. 2013) that was detected here. This is also demonstrated for Sebacinaceae (Selosse et al. 2009; Weiß et al. 2016), and remains pending for other ectomycorrhizal basidiomycetes (including Inocybe: Schneider-Maunoury et al. 2018). In this explanation, ectomycorrhizal mycelia may survive in pots by colonizing endophytically the roots of co-occurring weeds (Figs. 1 and 3) and/or E. helleborine.

\section{Isotopic and N signatures of autotrophy}

Whatever the reason for their presence, these root fungi did not provide detectable contribution to the biomass of the orchid since isotopic ${ }^{13} \mathrm{C}$ and ${ }^{15} \mathrm{~N}$ abundances as well as total $\mathrm{N}$ content were similar to those of surrounding autotrophic references. A very small flow, which would not entail significant deviations in isotopic abundances, may of course occur, but the $\mathrm{N}$ content, lower than that of autotrophic references, argues against this. This lack of apparent mycoheterotrophy is in good agreement with the paucity of ectomycorrhizal fungi in roots and the lack of nutritional resources for the few detected, because links to surrounding ectomycorrhizal hosts are regularly disturbed.

Mixotrophy in Neottiae (the orchid tribe encompassing Epipactis) may thus display some plasticity. The ratio of aerial biomass acquired by photosynthesis and mycoheterotrophy is reported to vary with the light level in mixotrophs: increasing light positively correlates with higher contribution of photosynthesis and, thus, a lower ${ }^{13} \mathrm{C}$ content (Preiss et al. 2010; Gonneau et al. 2014). Indeed, the site of pot cultivation is rather sunny, as shown by a relatively high Ellenberg's indicator value for light (value of 7 for a maximum of 9), and there is no competition for diffuse light with similarly high plants. A similar situation is sometimes reported for E. helleborine in 
full light, in open fields quite far away from nearest ectomycorrhizal trees (e.g., Rydlo 2008). We may have here an extreme of the continuum from mycohetero- to autotrophy, leading to undetectable mycoheterotrophy because of light level and lack of fungal resources. The possibility of autotrophic survival in E. helleborine is also congruent with the recent report that its plastid genome retains a full set of photosynthetic genes without any evidence of selective relaxation (Lallemand et al. 2019b) and has intact photosynthetic abilities. Moreover, the phylogenetically related mixotrophic Limodorum abortivum displayed some photosynthetic compensation (higher chlorophyll content and possibly higher photosynthetic activity) after experimental eradication of its fungal partners in situ (Bellino et al. 2014). Here, the lack of fungal resources in pots may have entailed a similar compensation.

In this framework, the observation of similar ${ }^{13} \mathrm{C}$ abundance in mycorrhizas and leaves is very relevant. As exemplified in the related mixotrophic Cephalanthera damasonium (Lallemand et al. 2019a), ${ }^{13} \mathrm{C}$-enrichment of mycorrhizal fungi and derived plant starch normally induce higher ${ }^{13} \mathrm{C}$ abundance in mycorrhizas than in leaves. In pot-cultivated E. helleborine, the two organs displayed similar abundances, which can be explained if (i) the underground carbon is photosynthetic in origin and (ii) there is little biomass of ectomycorrhizal fungi, either as hyphae or delivered to the root cells. Alternatively, but less likely, we cannot exclude that root fungi provide resources from a different nutrition, e.g., saprotrophic or endophytic, which would not entail isotopic differences as compared with photosynthetic resources (see below). Finally, this autotrophic signature for underground parts is somewhat unexpected in the current model of nutrition in mixotrophic Neottieae, where photosynthates are mostly used for aboveground parts (Bellino et al. 2014; Gonneau et al. 2014) and migrate poorly underground (Lallemand et al. 2019a). Yet, a small flow to underground parts exists in labeling experiments (Lallemand et al. 2019a) and we speculate that, in pots, the absence (or limited presence) of fungi entails a stronger sink that directs more plant $\mathrm{C}$ to roots than when nutrients flow from the mycorrhizal network. This may also mean that autotrophic life in E. helleborine requires quite high light levels, as in this study.

\section{Autotrophic survival in E. helleborine in evolution of mixotrophy}

Pot-cultivated E. helleborine displays three features that contrast with those of mixotrophy (as described in Section 1): (i) rhizoctonias, not ectomycorrhizal fungi, dominate in their roots and since an endophytic, non-ectomycorrhizal niche can be proposed for the few existing ones, there is likely no mycorrhizal network with surrounding plants; (ii) neither ${ }^{13} \mathrm{C}$ nor ${ }^{15} \mathrm{~N}$ abundances offer significant evidence for gain from the few available ectomycorrhizal fungi; (iii) their $\mathrm{N}$ content is not higher than that of surrounding autotrophs. This supports autotrophy in these specific conditions, for a species otherwise reported as mixotrophic in its natural environments.

There is currently an open question on autotrophy in rhizoctonia-associated orchids: their slight isotopic difference with surrounding autotrophs (Selosse and Martos 2014) as well as their ${ }^{2} \mathrm{H}$ abundance (Gebauer et al. 2016; Schiebold et al. 2018) suggests that they recover some fungal biomass. Yet, the net flow, i.e., when also considering the potential reverse flow from orchid to fungus, is unknown. One ex situ experiment involving Ceratobasidiaceae reveals a net flow in favor of the fungus (Cameron et al. 2008), and no achlorophyllous variants of rhizoctonia-associated orchid survive in nature. Thus, the question of the net contribution of rhizoctonias remains open (see discussion in Lallemand et al. 2017) and, to facilitate reading, we provisionally consider below rhizoctonia-associated orchids as "autotrophic." Potcultivated E. helleborine displays all the features of such orchids; even the presence of a few ectomycorrhizal fungi in the roots is reported from rhizoctonia-associated orchids (e.g., Jacquemyn et al. 2017). Our observations have consequences for plant protection and for the evolution of mixotrophy.

In terms of plant protection, ex situ conservation and transplantation is thus possible. The successful E. helleborine transplantation by Delforge, $(2016,2017)$, which this author explains by a reconnection to the mycorrhizal network, may have been helped by autotrophic survival, at least transiently. We show here that absence of mycorrhizal network may even not impair survival, at least transiently. The failed transplantations by Sadovsky (1965) may be due to two factors. Firstly, not all plants, and even not all populations, may have a physiological status allowing transplantation, as shown by the $60 \%$ survival in our study (see Section 2): more on the physiology and autotrophy level of the population of origin could help, but this was overlooked in this study, which was initially designed as a taxonomic study. Secondly, not all receiving sites may be suitable, e.g., in terms of light (see above): sunnier sites may be targeted to enhance photosynthesis, although a negative trade-off is possible with desiccation in the absence of an artificial cover, as in our garden. We are far from predicting the factors allowing transplantation of mixotrophs, and more data on transplantation of various mixotrophic species (which often stay in the "gray literature") are required to help save threatened populations.

In terms of evolution, one should remember that similar mycorrhizal, nitrogen, and isotopic features occur in closely related Epipactis species, such as E. palustris (Lallemand et al. 2018) and E. gigantea (Schiebold et al. 2017), which associate with Ceratobasidiaceae (Bidartondo et al. 2004; Jacquemyn et al. 2016, 2017). These Epipactis species belong to rhizoctonia-associated, putatively autotrophic orchids, and thus, an autotrophy-to-mixotrophy transition (or vice-versa) 
occurred in the evolution of the genus Epipactis. In the framework of Neottieae evolution as a whole, it is still unclear in which direction this transition occurred, and a reversion from mixo- to autotrophy is also possible (Lallemand et al. 2019b, c). Autotrophic survival in E. helleborine, combining the intact plastid genomes of mixotrophic orchids (retaining all photosynthetic genes; (Feng et al. 2016; Lallemand et al. 2019b), makes a reversion possible, even if the physiology of mixotrophs is deeply rooted in their dependence on two carbon sources, as mentioned above (Gonneau et al. 2014; Lallemand et al. 2019a).

Our findings add to the reported plasticity of mixotrophs: they are known to survive the disappearance of chlorophyll (achlorophyllous variants; e.g., Julou et al. 2005; Gonneau et al. 2014) and to adapt to light level (Preiss et al. 2010; Gonneau et al. 2014); they now turn out to display nearly autotrophic survival in some environments. Such nutritional plasticity is a major attribute for successional species, such as Epipactis species, which colonize early-stage forests with variable access to light and ectomycorrhizal networks. The mycorrhizal interaction with rhizoctonias in autotrophic orchids versus ectomycorrhizal fungi in mixotrophs recently turned out to be a continuum rather than an alternative (Jacquemyn et al. 2017, and references therein); autotrophic versus mixotrophic nutrition also turns out to be a continuum, even within a given species. A quite similar statement was made in the mixotrophic Pyrola japonica under different light environments (Matsuda et al. 2012), in the Ericaceae family where mixotrophs are considered transplantable (Figura et al. 2019). Thus, autotrophic survival of mixotrophs may be sought in various phylogenetic backgrounds, even beyond orchids.

\section{Conclusion}

Some mixotrophic E. helleborine can be cultivated in pots, where they behave as autotrophs. Many other mixotrophic orchids may have a high trophic plasticity that was overlooked till now. They display reduced mycorrhizal colonization by the fungi that usually link them to surrounding trees, and from which they indirectly extract part of their carbon resources in forest (mixotrophy). Instead, they associate with rhizoctonia taxa that normally colonize autotrophy orchids. This further suggests that mixotrophy is ecologically, if not evolutionarily, plastic.

Acknowledgments The authors would like to acknowledge Dietrich Bergfeld and Werner Hiller, who helped us to collect and determine subspecies, two anonymous referees that improved the previous version of this manuscript, and the gardeners of the Botanical Garden Ulm. They also thank David Marsh for English editing and the Fondation de France for support to Marc-André Selosse's lab in Paris.
Funding information This study was financially supported by the Arbeitskreis heimische Orchideen Baden-Württemberg (AHO).

Open Access This article is licensed under a Creative Commons Attribution 4.0 International License, which permits use, sharing, adaptation, distribution and reproduction in any medium or format, as long as you give appropriate credit to the original author(s) and the source, provide a link to the Creative Commons licence, and indicate if changes were made. The images or other third party material in this article are included in the article's Creative Commons licence, unless indicated otherwise in a credit line to the material. If material is not included in the article's Creative Commons licence and your intended use is not permitted by statutory regulation or exceeds the permitted use, you will need to obtain permission directly from the copyright holder. To view a copy of this licence, visit http://creativecommons.org/licenses/by/4.0/.

\section{References}

Abadie JC, Püttsepp Ü, Gebauer G, Faccio A, Bonfante P, Selosse M-A (2006) Cephalanthera longifolia (Neottieae, Orchidaceae) is mixotrophic: a comparative study between green and nonphotosynthetic individuals. Can J Bot 84:1462-1477

Almario J, Jeena G, Wunder J, Langen G, Zuccaro A, Coupland G, Bucher M (2017) Root-associated fungal microbiota of nonmycorrhizal Arabis alpina and its contribution to plant phosphorus nutrition. Proc Natl Acad Sci U S A 114:E9403-E9412

Altschul SF, Gish W, Miller W, Myers EW, Lipman DJ (1990) Basic local alignment search tool. J Mol Biol 215:403-410

Bellino A, Alfani A, Selosse MA, Guerrieri R, Borghetti M, Baldantoni D (2014) Nutritional regulation in mixotrophic plants: new insights from Limodorum abortivum. Oecologia 175:875-885

Bidartondo MI, Burghardt B, Gebauer G, Bruns TD, Read DJ (2004) Changing partners in the dark: isotopic and molecular evidence of ectomycorrhizal liaisons between forest orchids and trees. Proc R Soc London, Ser B 271:1799-1806

Cameron DD, Johnson I, Read DJ, Leake JR (2008) Giving and receiving: measuring the carbon cost of mycorrhizas in the green orchid Goodyera repens. New Phytol 180:176-184

Caporaso JG, Kuczynski J, Stombaugh J, Bittinger K, Bushman FD, Costello EK, Fierer N, Peña AG, Goodrich JK, Gordon JI, Huttley GA, Kelley ST, Knights D, Koenig JE, Ley RE, Lozupone CA, McDonald D, Muegge BD, Pirrung M, Reeder J, Sevinsky JR, Turnbaugh PJ, Walters WA, Widmann J, Yatsunenko T, Zaneveld J, Knight R (2010) QIIME allows analysis of high-throughput community sequencing data. Nat Methods 7:335-336

Cosme M, Fernández I, Van der Heijden MGA, Pieterse CMJ (2018) Non-mycorrhizal plants: the exceptions that prove the rule. Trends Plant Sci 23:577-587

Dearnaley JDW, Martos F, Selosse M-A (2012) Orchid mycorrhizas: molecular ecology, physiology, evolution and conservation aspects. In: Hock B (ed) The Mycota IX: fungal associations, 2nd edn. Springer, Berlin, pp 207-230

Delforge P (2016) Que devient un individu robuste d'Epipactis helleborine ( $\mathrm{L}$.) Crantz après une transplantation réussie ? Implications pour le statut d' $E$. helleborine var . minor Engel et d'E. helleborine. Nat Belges 97:89-124

Delforge P (2017) Que devient en 2017 un individu robuste d'Epipactis helleborine ( L .) C RANTZ après une transplantation réussie, effectuée en 2011 ? Nat Belges 98:62-68

Edgar RC, Haas BJ, Clemente JC, Quince C, Knight R (2011) UCHIME improves sensitivity and speed of chimera detection. Bioinformatics 27:2194-2200 
Ellenberg H, Weber EH, Düll R, Wirth V, Werner W, Paulißen D (1991) Zeigerwerte von Pflanzen in Mitteleuropa. Scr Geobot 18:1-248

Feng YL, Wicke S, Li JW, Han Y, Lin CS, Li DZ, Zhou TT, Huang WC, Huang LQ, Jin XH (2016) Lineage-specific reductions of plastid genomes in an orchid tribe with partially and fully mycoheterotrophic species. Genome Biol Evol 8:2164-2175

Figura T, Tylová E, Šoch J, Selosse MA, Ponert J (2019) In vitro axenic germination and cultivation of mixotrophic Pyroloideae (Ericaceae) and their post-germination ontogenetic development. Ann Bot 123: 625-639

Gebauer G, Meyer M (2003) ${ }^{15} \mathrm{~N}$ and ${ }^{13} \mathrm{C}$ natural abundance of autotrophic and myco-heterotrophic orchids provides insight into nitrogen and carbon gain from fungal association. New Phytol 160:209-223

Gebauer G, Preiss K, Gebauer AC (2016) Partial mycoheterotrophy is more widespread among orchids than previously assumed. New Phytol 211:11-15

Girlanda M, Selosse MA, Cafasso D, Brilli F, Delfine S, Fabbian R, Ghignone S, Pinelli P, Segreto R, Loreto F, Cozzolino S, Perotto S (2006) Inefficient photosynthesis in the Mediterranean orchid Limodorum abortivum is mirrored by specific association to ectomycorrhizal Russulaceae. Mol Ecol 15:491-504

Gonneau C, Jersáková J, de Tredern E, Till-Bottraud I, Saarinen K, Sauve M, Roy M, Hájek T, Selosse M-A (2014) Photosynthesis in perennial mixotrophic Epipactis spp. (Orchidaceae) contributes more to shoot and fruit biomass than to hypogeous survival. J Ecol 102: 1183-1194

Gryndler M, Černá L, Bukovská P, Hršelová H, Jansa J (2014) Tuber aestivum association with non-host roots. Mycorrhiza 24:603-610

Hansen K, Perry BA, Dranginis AW, Pfister DH (2013) A phylogeny of the highly diverse cup-fungus family Pyronemataceae (Pezizomycetes, Ascomycota) clarifies relationships and evolution of selected life history traits. Mol Phylogenet Evol 67:311-335

Hynson NA, Madsen TP, Selosse M-A, Adam IKU, Ogura-Tsujita Y, Roy M, Gebauer G (2013) The physiological ecology of mycoheterotrophy. In: Merckx VSFT (ed) Mycoheterotrophy. Springer, New York, pp 297-342

Jacquemyn H, Merckx VSFT (2019) Mycorrhizal symbioses and the evolution of trophic modes in plants. J Ecol 107:1567-1581

Jacquemyn H, Waud M, Lievens B, Brys R (2016) Differences in mycorrhizal communities between Epipactis palustris, E. helleborine and its presumed sister species E. neerlandica. Ann Bot 118:105-114

Jacquemyn H, Waud M, Brys R, Lallemand F, Courty PE, Robionek A, Selosse M-A (2017) Mycorrhizal associations and trophic modes in coexisting orchids: an ecological continuum between auto-and mixotrophy. Front Plant Sci 8:1-12

Julou T, Burghardt B, Gebauer G, Berveiller D, Damesin C, Selosse M-A (2005) Mixotrophy in orchids: insights from a comparative study of green individuals and nonphotosynthetic individuals of Cephalanthera damasonium. New Phytol 166:639-653

Jumpponen A (2001) Dark septate endophytes - are they mycorrhizal? Mycorrhiza 11:207-211

Kõljalg U, Nilsson RH, Abarenkov K, Tedersoo L, Taylor AFS, Bahram M, Bates ST, Bruns TD, Bengtsson-Palme J, Callaghan TM, Douglas B, Drenkhan T, Eberhardt U, Dueñas M, Grebenc T, Griffith GW, Hartmann M, Kirk PM, Kohout P, Larsson E, Lindahl BD, Lücking R, Martín MP, Matheny PB, Nguyen NH, Niskanen T, Oja J, Peay KG, Peintner U, Peterson M, Põldmaa K, Saag L, Saar I, Schüßler A, Scott JA, Senés C, Smith ME, Suija A, Taylor DL, Telleria MT, Weiss M, Larsson KH (2013) Towards a unified paradigm for sequence-based identification of fungi. Mol Ecol 22:5271-5277

Lallemand F, Puttsepp Ü, Lang M, Luud A, Courty PE, Palancade C, Selosse M-A (2017) Mixotrophy in Pyroleae (Ericaceae) from Estonian boreal forests does not vary with light or tissue age. Ann Bot 120:361-371
Lallemand F, Robionek A, Courty PE, Selosse M-A (2018) The ${ }^{13} \mathrm{C}$ content of the orchid Epipactis palustris (L.) Crantz responds to light as in autotrophic plants. Bot Lett 165:265-273

Lallemand F, Figura T, Damesin C, Fresneau C, Griveau C, Fontaine N, Zeller B, Selosse M-A (2019a) Mixotrophic orchids do not use photosynthates for perennial underground organs. New Phytol 221:12-17

Lallemand F, Logacheva M, Le Clainche I, Bérard A, Zheleznaia E, May M, Jakalski M, Delannoy É, Le Paslier M-C, Selosse M-A (2019b) Thirteen new plastid genomes from mixotrophic and autotrophic species provide insights into heterotrophy evolution in Neottieae orchids. Genome Biol Evol:49-66

Lallemand F, Martin-Magniette ML, Gilard F, Gakière B, Launay-Avon A, Delannoy E, Selosse M-A (2019c) In situ transcriptomic and metabolomic study of the loss of photosynthesis in the leaves of mixotrophic plants exploiting fungi. Plant J 98:826-841

Lewis L (2015) Some observations on the nomenclature of achlorophyllous forms of Epipactis purpurata, E. helleborine and E. dunensis. J Eur Orchid 47:111-122

Mahé F, Rognes T, Quince C, de Vargas C, Dunthorn M (2014) Swarm: robust and fast clustering method for amplicon-based studies. PeerJ 2014:1-13

Matsuda Y, Shimizu S, Mori M, Ito S-I, Selosse M-A (2012) Seasonal and environmental changes of mycorrhizal associations and heterotrophy levels in mixotrophic Pyrola japonica (Ericaceae) growing under different light environments. Am J Bot 99:1177-1188

Ogura-Tsujita Y, Yukawa T (2008) Epipactis helleborine shows strong mycorrhizal preference towards ectomycorrhizal fungi with contrasting geographic distributions in Japan. Mycorrhiza 18:331-338

Preiss K, Adam IKU, Gebauer G (2010) Irradiance governs exploitation of fungi: fine-tuning of carbon gain by two partially mycoheterotrophic orchids. Proc R Soc London, Ser B 277:1333-1336

R Core Team (2015). R: A language and environment for statistical computing. R Foundation for Statistical Computing, Vienna, Austria. http://www.R-project.org/. Accessed 6 Oct 2019

Roy M, Gonneau C, Rocheteau A, Berveiller D, Thomas JC, Damesin C, Selosse M-A (2013) Why do mixotrophic plants stay green? A comparison between green and achlorophyllous orchid individuals in situ. Ecol Monogr 83:95-117

Rydlo J (2008) Epipactis helleborine jako polni plevel. Muz a Současnost, Roztoky, ser natur 23:211-218

Sadovsky O (1965) Orchideen im eigenen Garten. Bayer, Landwirtschaftsverlag

Salmia A (1989) General morphology and anatomy of chlorophyll-free and green forms of Epipactis helleborine (Orchidaceae). Ann Bot Fenn 26:95-105

Schiebold JMI, Bidartondo MI, Karasch P, Gravendeel B, Gebauer G (2017) You are what you get from your fungi: nitrogen stable isotope patterns in Epipactis species. Ann Bot 119:1085-1095

Schiebold JMI, Bidartondo MI, Lenhard F, Makiola A, Gebauer G (2018) Exploiting mycorrhizas in broad daylight: partial mycoheterotrophy is a common nutritional strategy in meadow orchids. J Ecol 106: $168-178$

Schneider-Maunoury L, Leclercq S, Clément C, Covès H, Lambourdière J, Sauve M, Richard F, Selosse MA, Taschen E (2018) Is Tuber melanosporum colonizing the roots of herbaceous, nonectomycorrhizal plants? Fungal Ecol 31:59-68

Schneider-Maunoury L, Deveau A, Moreno M, Todesco F, Belmondo S, Murat C, Courty P-E, Jąkalski M, Selosse M-A (2019) Two ectomycorrhizal truffles, Tuber melanosporum and T. aestivum, endophytically colonise roots of non-ectomycorrhizal plants in natural environments. New Phytol in press

Selosse MA, Martos F (2014) Do chlorophyllous orchids heterotrophically use mycorrhizal fungal carbon? Trends Plant Sci 19:683-685

Selosse MA, Roy M (2009) Green plants that feed on fungi: facts and questions about mixotrophy. Trends Plant Sci 14:64-70 
Selosse MA, Faccio A, Scappaticci G, Bonfante P (2004) Chlorophyllous and achlorophyllous specimens of Epipactis microphylla (Neottieae, Orchidaceae) are associated with ectomycorrhizal septomycetes, including truffles. Microb Ecol 47:416-426

Selosse MA, Richard F, He X, Simard SW (2006) Mycorrhizal networks: des liaisons dangereuses? Trends Ecol Evol 21:621-628

Selosse MA, Dubois MP, Alvarez N (2009) Do Sebacinales commonly associate with plant roots as endophytes? Mycol Res 113:10621069

Selosse MA, Bocayuva MF, Kasuya MCM, Courty P-E (2016) Mixotrophy in mycorrhizal plants: extracting carbon from mycorrhizal networks. In: Martinn F (ed) Molecular mycorrhizal symbiosis. Springer, Berlin, pp 451-471

Selosse MA, Schneider-Maunoury L, Martos F (2018) Time to re-think fungal ecology? Fungal ecological niches are often prejudged. New Phytol 217:968-972

Shefferson RP, Roy M, Püttsepp Ü, Selosse M-A (2016) Demographic shifts related to mycoheterotrophy and their fitness impacts in two Cephalanthera species. Ecology 97:1452-1462

Simard SW, Beiler KJ, Bingham MA, Deslippe JR, Philip LJ, Teste FP (2012) Mycorrhizal networks: mechanisms, ecology and modelling. Fungal Biol Rev 26:39-60

Tedersoo L, Smith ME (2013) Lineages of ectomycorrhizal fungi revisited: foraging strategies and novel lineages revealed by sequences from belowground. Fungal Biol Rev 27:83-99

Tedersoo L, May TW, Smith ME (2010) Ectomycorrhizal lifestyle in fungi: global diversity, distribution, and evolution of phylogenetic lineages. Mycorrhiza 20:217-263
Těšitelová T, Teššitel J, Jersáková J, Ř́íhová G, Selosse M-A (2012) Symbiotic germination capability of four Epipactis species (Orchidaceae) is broader than expected from adult ecology. Am J Bot 99:1020-1032

Wang Z, Johnston PR, Takamatsu S, Spatafora JW, Hibbett DS (2006) Toward a phylogenetic classification of the Leotiomycetes based on rDNA data. Mycologia 98:1065-1075

Wang XH, Benucci GMN, Xie XD, Bonito G, Leisola M, Liu PG, Shamekh S (2013) Morphological, mycorrhizal and molecular characterization of Finnish truffles belonging to the Tuber anniae species-complex. Fungal Ecol 6:269-280

Waud M, Busschaert P, Ruyters S, Jacquemyn H, Lievens B (2014) Impact of primer choice on characterization of orchid mycorrhizal communities using 454 pyrosequencing. Mol Ecol Resour 14:679699

Weiß M, Waller F, Zuccaro A, Selosse M-A (2016) Sebacinales - one thousand and one interactions with land plants. New Phytol 211:2040

Wilson D (1995) Endophyte: the evolution of a term, and clarification of its use and definition. Oikos 73:274-276. https://doi.org/10.2307/ 3545919

Xing X, Gao Y, Zhao Z, Waud M, Duffy KJ, Selosse M, Jakalski M, Liu N, Jacquemyn H, Guo S, Merckx V, (2019) Similarity in mycorrhizal communities associating with two widespread terrestrial orchids decays with distance. Journal of Biogeography

Publisher's note Springer Nature remains neutral with regard to jurisdictional claims in published maps and institutional affiliations. 